\title{
Uptake and translocation of lesser-chlorinated polychlorinated biphenyls (PCBs) in whole hybrid poplar plants after hydroponic exposure
}

\author{
Jiyan Liu ${ }^{\mathrm{a}, \mathrm{b}}$, Jerald L. Schnoor ${ }^{\mathrm{a}, *}$ \\ ${ }^{a}$ Department of Civil and Environmental Engineering, University of Iowa, 103 South Capitol Street, Iowa City, Iowa 52242, USA

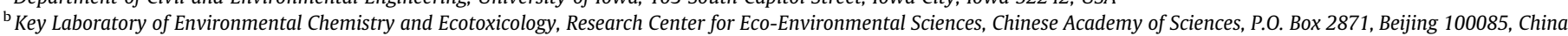

\section{A R T I C L E I N F O}

\section{Article history:}

Received 10 April 2008

Received in revised form 29 July 2008

Accepted 11 August 2008

Available online 14 September 2008

\section{Keywords:}

Polychlorinated biphenyls (PCBs)

Phytoremediation

Poplar

\begin{abstract}
A B S T R A C T
Mono-, di-, tri-, and tetra-chlorinated polychlorinated biphenyls (PCBs) are congeners with greater volatility which remain in air, soils and sediments requiring treatment. In this study, the fate of these PCBs was investigated within whole poplar plants (Populus deltoides $x$ nigra, DN34) with application for a treatment system such as a confined disposal facility for dredged material. Whole hybrid poplars were exposed hydroponically to a mixture of five congeners, common in the environment, having one to four chlorine atoms per molecule. Results indicated that PCB 3, 15, 28, 52, and 77 were initially sorbed to the root systems. The root concentration factor (RCF) of PCBs during the exposure was calculated and correlated with $K_{\mathrm{ow}}$. PCB congeners were taken up by the roots of hybrid poplar, and the translocation of PCBs to stems was inversely related to congener hydrophobicity $\left(\log \mathrm{K}_{\mathrm{ow}}\right)$. PCB 3 and 15 were translocated to the upper stem at small but significant rates. PCB 28 was translocated to the wood of the main stem but no farther; translocation from the roots was not detected for PCB 52 and 77. The distribution of PCBs within poplars was determined, and mass balances were completed to within $15 \%$ for each chemical except for PCB 3, the most volatile congener. This is the first report on the transport of PCBs through whole plants designed for use in treatment at disposal facilities.
\end{abstract}

(c) 2008 Elsevier Ltd. All rights reserved.

\section{Introduction}

Polychlorinated biphenyls (PCBs) were manufactured and widely used until 1979. PCBs are comprised of 209 highly stable congeners with various physical and chemical properties depending on the number and positions of chlorine substitutes on the biphenyl ring. The high lipophilicity and persistence in the environment allows PCBs to bioaccumulate and biomagnify in the food chain and resist biodegradation. PCBs have been found everywhere on the earth including the Arctic and Antarctic (Risebrough et al., 1976). They are considered priority soil contaminants because of their tendency to persist in soil and sediments. Long-term contaminated soil often displays a higher proportion of high chlorinated congeners (Mackova et al., 2006). PCBs in the air are commonly dominated by the lesser-chlorinated congeners due to their greater volatility, although higher chlorinated congeners are also regularly observed (Hornbuckle et al., 2006). Increasing concerns over PCBs have focused on reducing the environmental risk of PCBs to human beings. Dredged materials from harbors contain a mixture of volatile and semi-volatile congeners which require treatment (Tang and Myers, 2002).

\footnotetext{
* Corresponding author. Tel.: +1 319335 5649; fax: +1 3193355660 .

E-mail address: jschnoor@engineering.uiowa.edu (J.L. Schnoor).
}

Phytoremediation is the use of vegetation for in situ treatment of soil, sediment, and water, and has been applied successfully in sites contaminated by organic or metal pollutants (Schnoor et al., 1995; Hughes et al., 1997). This popular remediation method is cost-effective, aesthetically pleasing, and suitable for large areas over long period of time. However, phytoremediation studies for PCBs are very limited. Past plant-PCBs interaction experiments examined food chain transfer and focused on crops and vegetables (Webber et al., 1990; Gan and Berthouex, 1994). For example, the uptake and translocation of PCBs was reported within corn (Zea mays L.), cabbages (Brassica oleracea var. capotata L.), carrots (Daucus carota L.) (Webber et al., 1990; Iwata and Gunther, 1976), squash (C. pepo ssp ovifera), zucchini (C. pepo ssp pepo) (White et al., 2006), beets (Beta vulgaris), turnips (Barssica rapa L.) and beans (Phaseolus vulgaris) (Sawhney and Hankin, 1984), but not in soybeans (Glycine max) (Fries and Marrow, 1981). Previous studies showed that there is a remarkable diversity in uptake and transportation of organic pollutants in plants, dependent not only on the specific properties of each compound but also on the characteristics of the plant species. Whitfield-Aslund et al. (2007) reported that pumpkins (Cucurbita pepo ssp pepo $c v$.) can take up and translocate PCBs from soil. It was also observed that zucchini fruits (Cucurbita pepo ssp pepo cv. giromontiina) accumulated two orders of magnitude more polychlorinated dibenzo-p-dioxins and dibenzofurans than other fruits and vegetables in the same 
contaminated site (Hulster et al., 1994). The variability and the interaction between plants and chemicals are presently not well understood.

In this research, hybrid poplar plants were used to study the possibility of applying phytoremediation for $\mathrm{PCB}$ contamination, especially to mono-, di-, tri- and tetra-chlorinated PCBs present in contemporary air and sediments. Hybrid poplar trees are candidate treatment system for uptake and remediation at dredged material disposal sites where they would be exposed to PCBs in slurry-mixtures through their root systems, analogous to the hydroponic exposure system used in this experiment. Mono-, di-, tri- and tetra-chlorinated PCB congeners that are found in Chicago air and sediment samples were selected as analytes for this study. To understand the fate of these PCBs within plants, the uptake and translocation of individual congeners in poplars were analyzed.

\section{Experimental design}

\subsection{Chemicals}

Five low-chlorinated biphenyl congeners were selected for hydroponic exposure, including PCB 3 (4-monochlorobiphenyl), PCB 15 (4,4'-dichlorobiphenyl), PCB 28 (2,4,4'-trichlorobiphenyl),

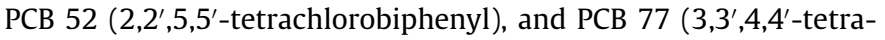
chlorobiphenyl) (IUPAC number). Their properties are listed in Supplementary material (Table S1). These congeners have not been widely studied for phytoremediation and are known to be important components of Chicago air (Hornbuckle et al., 2006). They are persistent in the environment and are suspected toxicants in humans (Ptak et al., 2006; Maddox et al., 2008). Congener PCB 14 (3,5-dichlorobiphenyl) (IUPAC number) was used as a surrogate standard for quantitative analysis. All the above PCB standards
(98\% pure or better) were obtained from the NIEHS Superfund Basic Research Program Center at the University of Iowa. Individual stock standard solutions of PCB 3, PCB 15, PCB 28, and PCB 52 at $5 \mathrm{mg} \mathrm{mL}^{-1}$, PCB 77 at $1 \mathrm{mg} \mathrm{mL}^{-1}$, PCB 14 at $0.4 \mathrm{mg} \mathrm{mL}^{-1}$ as compounds were prepared using acetone as the solvent. Working solutions were prepared by diluting the stock solutions gradually with acetone (for preparing hydroponic solutions) or hexane (for gas chromatography injection). As internal standard, PCB 30 (2,4,6-trichlorobiphenyl) $\left(100 \mu \mathrm{g} \mathrm{mL}^{-1}\right.$ in isooctane) was purchased from Cambridge Isotope Laboratories, Inc. and diluted with hexane to $10 \mu \mathrm{g} \mathrm{mL}^{-1}$ before use. All standards and solutions were stored hermetically in amber glass vials at room temperature in the dark.

Silica gel (70-230 mesh, Fisher Scientific Inc.) was activated at $450{ }^{\circ} \mathrm{C}$ for $12 \mathrm{~h}$ and then transferred to a desiccator for cooling. Acid silica gel was prepared by blending $50 \mathrm{~g}$ of concentrated $\mathrm{H}_{2} \mathrm{SO}_{4}$ with $100 \mathrm{~g}$ of activated silica gel.

Acetone (HPLC grade) was purchased from Sigma. Methyl-tert butyl ether (MTBE) (HPLC grade) and hexane (pesticide grade) were purchased from Fisher scientific. All other chemicals and reagents used in this experiment were of analytical reagent grade or better.

\subsection{Hydroponic exposure}

The exposure system was designed to allow estimation of mass balances on individual PCB congeners while providing hydroponic exposure, somewhat analogous to that experienced by poplar trees planted in dredged material slurry at a confined disposal facility (CDF). Cuttings (around $20 \mathrm{~cm}$ long) from male clones of the adult Imperial Carolina hybrid poplar tree (Populus deltoides $\times$ nigra, DN34) were affixed with pre-drilled screw caps and pre-drilled PTFE-faced septa. Silicon sealant was applied to seal the interface of the septa and cutting. The cuttings were grown hydroponically

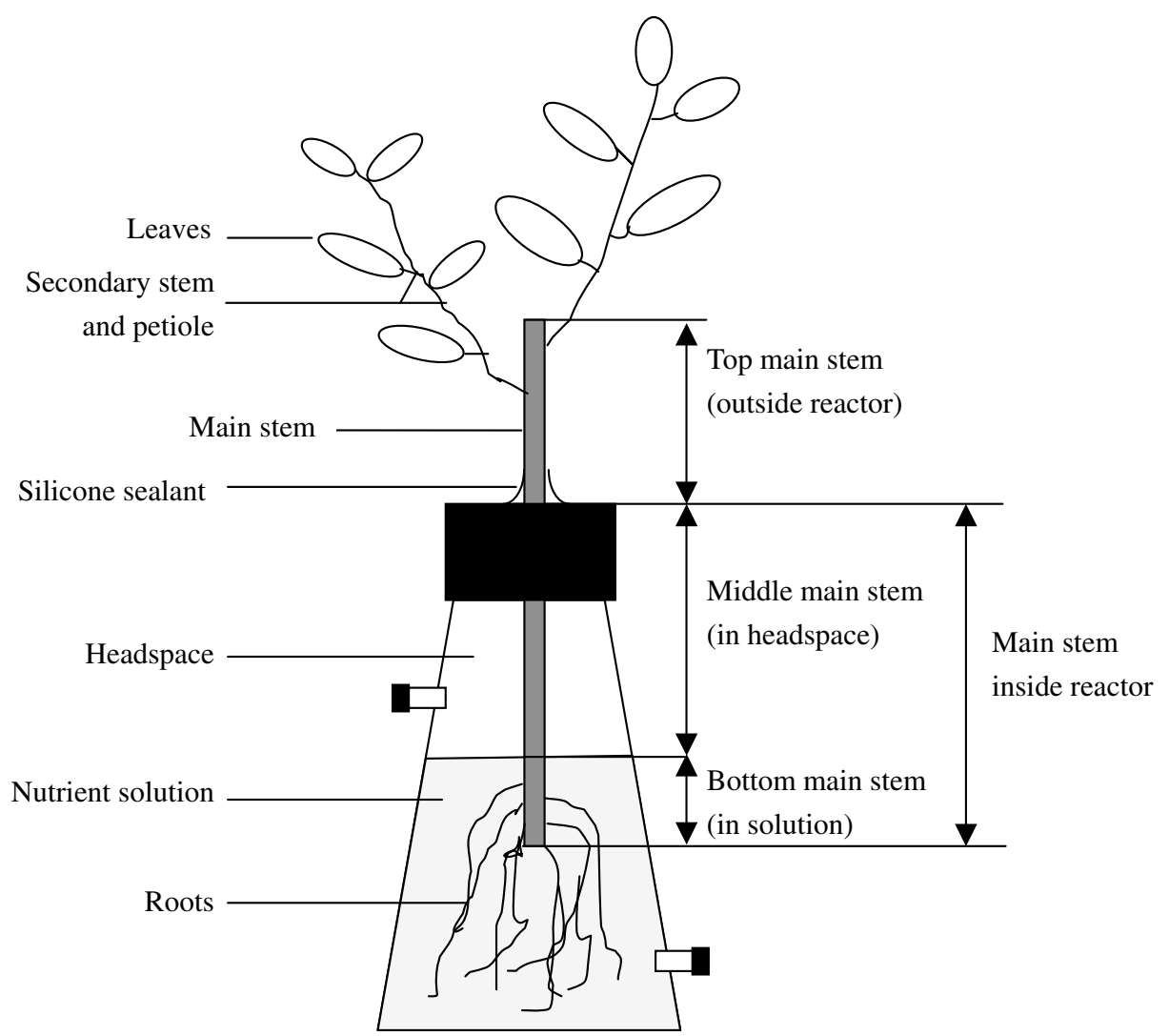

Fig. 1. Schematic of the hydroponic exposure reactor and sampling. 
in a growth chamber using inorganic half strength Hoagland nutrient solution (Epstein, 1972) which was adjusted to $\mathrm{pH} 6.5$ by $1.0 \mathrm{~N}$ $\mathrm{NaOH}$. After 25 days, cuttings developed enough branches, leaves, and dense roots to conduct experiments (30-35 cm in height).

Modified 500-mL glass screw-top conical flasks (two sampling ports with PTFE-faced silicon septa and pre-drilled screw caps) were used as exposure reactors for these experiments (Fig. 1). Autoclaved reactors were filled with $0.4 \mathrm{~kg}$ of half strength Hoagland solution prepared with autoclaved ionized water. Standard solutions of selected PCBs, dissolved in acetone, were added to make aqueous solutions of mixed PCBs with concentrations of $1 \mathrm{mg} \mathrm{kg}^{-1}$ PCB 3, $0.1 \mathrm{mg} \mathrm{kg}^{-1}$ PCB 15, $0.05 \mathrm{mg} \mathrm{kg}^{-1}$ PCB 28 and PCB 52, and $0.01 \mathrm{mg} \mathrm{kg}^{-1}$ PCB 77. The initial concentrations were lower than the water solubility of all congeners, with the exception of PCB 77 whose initial concentration was 10 times higher than its solubility. We chose these concentrations because they were less than solubility but high enough to provide a good chromatographic signal even when sorbed to plant tissues. The low solubility congener, PCB 77, could be detected simultaneously in a mixture of congeners by using supersaturated solutions.

Pre-grown whole poplar plants were planted into the reactors, and the reactors were fitted with screw caps and septa affixed on cuttings to minimize evaporation loss of PCBs. The tops of some whole poplar plants were cut off just above the caps to create excised tree controls. These reactors had no significant evapotranspiration and served to test the sorption of PCBs to roots and main stems, as well as the volatilization of PCBs from the reactor. Glass rods were used as unplanted controls to check PCB volatilization loss and sorption to glass. Blank whole poplar plant controls, without PCBs in the hydroponic solutions, were used to control for the sorption of volatilized PCBs to leaves and secondary stems from ambient air in the laboratory. All reactors were wrapped with aluminum foil and placed in a fume hood with $33.5 \mathrm{~m} \mathrm{~min}^{-1}$ air speed. The air temperature during plant growth and exposure was maintained at $23 \pm 1{ }^{\circ} \mathrm{C}$, and the photoperiod was $16 \mathrm{~h}$ of light and $8 \mathrm{~h}$ of darkness.

Reactors were weighed daily to determine the loss of solution due to transpiration, and an equivalent mass of sterilized de-ionized water was injected into reactors through the sampling port to replace any losses. Five exposed whole poplar plants and a group of controls, including three unplanted controls, three excised controls and one blank control, were sacrificed and destructively sampled at 2, 5, 10, 15, and 20 days, respectively. The biomass for individual whole poplar plants was measured regularly. Hydroponic solutions, silicon sealant, and various plant components, including the roots, main stem, secondary stem and petioles, and leaves were sampled and analyzed. Dissolved oxygen (D.O.) was not measured but previous experiments in our laboratory would indicate that D.O. concentrations would be depleted after a few days, and it is presumed that the solutions became anoxic over time.

\section{Sampling and analytical methods}

\subsection{Sampling}

The bottoms of the main stems and roots were rinsed with flowing de-ionized water before sampling. Rinse water was combined with the hydroponic solution. Fresh plant samples were weighed, cut, and chopped with stainless steel blades and scissors, then ground to a fine powder in liquid nitrogen using a ceramic mortar and pestle. All the equipment was rinsed with reagentgrade acetone between samples to minimize cross-contamination. The leaves, the secondary stem and petioles of individual whole plants were sampled and stored in sterile screw cap tubes (Sarstedt
Inc., Newton, NC, USA) at $-80^{\circ} \mathrm{C}$ until analysis. The main stems of the exposed whole poplars which were sampled at 10,15 , and 20 days were divided into two portions, the main stem outside the reactor and the main stem inside the reactor. The main stems of exposed whole poplars which were sampled at two and five days, the excised controls, and the blank controls were not divided. To study the uptake and translocation of PCBs in more detail, the main stems of two exposed whole poplar plants sampled at day 20 were subdivided into the top portion (outside the reactor), middle portion (in the headspace of the reactor), and bottom portion (immersed in solution) (Fig. 1); each portion was sampled as bark and wood. To distinguish the PCBs sorbed on the surface of the root and absorbed into the root, intact and powdered roots from single plants were extracted immediately after sampling. The remaining roots were stored at $-80^{\circ} \mathrm{C}$. The silicon sealant was chopped into small pieces $(<2 \mathrm{~mm})$ for analysis.

\subsection{Extraction and cleanup}

Suitable amounts of surrogate standard (PCB 14) were added to all of the tested samples before extraction. Extraction was performed as described by Sporring and Wyrzykowska et al. (Sporring et al., 2005; Wyrzykowska et al., 2006). Briefly, $50 \mathrm{~mL}$ of hexane/ $\operatorname{MTBE}(1: 1 v / v)$ was poured into the reactor, and shaken violently for 30 min to extract the PCBs in the hydroponic solution. This extraction was performed twice. The combined $100 \mathrm{~mL}$ of extract was concentrated to about $1 \mathrm{~mL}$ by rotary evaporation at $40^{\circ} \mathrm{C}$. The extract was then partitioned with $1 \mathrm{~mL}$ of concentrated $\mathrm{H}_{2} \mathrm{SO}_{4}$ to remove the proteins, lipids, and any trace water. After centrifugation ( $5 \mathrm{~min}$ at $3000 \mathrm{rpm}$ ), the organic phase was transferred and mixed with the internal standard (PCB 30) for GC analysis.

Plant tissue and sealant samples were ultrasonicated for $15 \mathrm{~min}$ and shaken vigorously for $15 \mathrm{~min}$ after $3 \mathrm{~mL}$ of hexane/acetone $(1: 1, v / v) \mathrm{g}^{-1}$ of sample was added. The sample was centrifuged (10 min at $3000 \mathrm{rpm})$, and the organic extract was transferred. A second extraction was performed with $3 \mathrm{~mL}$ of hexane $\mathrm{g}^{-1}$ of sample. The combined extract was concentrated to $1 \mathrm{~mL}$, and treated with 1-2 mL of concentrated $\mathrm{H}_{2} \mathrm{SO}_{4}$. The acidic phase was reextracted with $1 \mathrm{~mL}$ of hexane after centrifugation and transferring of the organic phase. The combined organic phase was concentrated and transferred to a column of $1 \mathrm{~g}$ of acid silica gel with $0.1 \mathrm{~g}$ activated silica gel in the bottom. PCB congeners were eluted with $10 \mathrm{~mL}$ of hexane. The eluant was concentrated and mixed with internal standard (PCB 30) for GC analysis.

\subsection{Instrument analysis}

Quantitative analysis of PCBs was performed by an Agilent 6890 gas chromatography equipped with ${ }^{63} \mathrm{Ni}$ electron capture detector $(\mathrm{GC} / \mu \mathrm{ECD})$. Injections were performed using an autosampler device. A HP-5 fused silica capillary column ( $5 \%$ phenyl methyl siloxane, $30.0 \mathrm{~m} \times 250 \mu \mathrm{m} \times 1.00 \mu \mathrm{m}$ ) served to separate congeners. The GC-ECD was operated as follows: injection port, $250^{\circ} \mathrm{C}$ with splitless mode; high purity of helium carrier gas at $1 \mathrm{~mL} \mathrm{~min}{ }^{-1}$ constant flow rate; detector, $300{ }^{\circ} \mathrm{C}$; $95 \%$ argon and $5 \%$ methane make-up gas at $60 \mathrm{~mL} \mathrm{~min}^{-1}$ flow rate. The oven program was set for: $2 \mathrm{~min}$ at $70^{\circ} \mathrm{C}$, first ramp at $10^{\circ} \mathrm{C} \mathrm{min}-1$ to $200{ }^{\circ} \mathrm{C}$ (17 min hold), second ramp at $3^{\circ} \mathrm{C} \mathrm{min}^{-1}$ to $260{ }^{\circ} \mathrm{C}$ ( 1 min hold), and post run for $5 \mathrm{~min}$ at $300^{\circ} \mathrm{C}$. Peaks were identified by comparing their retention time with standards.

Only one surrogate standard, PCB 14 , was necessary because selected congeners had a maximum of four chlorine substituents. The mass recoveries of $\mathrm{PCB} 14$ for aqueous and plant tissue samples ranged from $80 \%$ to $117 \%$ and from $73 \%$ to $109 \%$, respectively. Reproducibility of the extraction method was verified using paral- 
lel extraction of root samples from single whole plants. The relative standard deviation for different congeners ranged from $5.0 \%$ to $10.8 \%$.

\section{Results and discussion}

\subsection{Plant growth}

Previous investigators concluded that plants can withstand PCB-contaminated soil with concentrations as high as $100 \mathrm{mg}$ total PCB kg$~^{-1}$ soil. Chlorosis of leaves and curling of leaf fringes became conspicuous in $\geqslant 1000 \mathrm{mg} \mathrm{kg}^{-1}$ PCB-contaminated soil (Weber and Mrozek, 1979; Zeeb and Amphlett, 2006; Whitfield-Aslund et al., 2007). In this hydroponic experiment, all whole poplar plants survived until being sacrificed at a maximum initial concentration of total PCB equal to $1.21 \mathrm{mg} \mathrm{kg}^{-1}$. Compared with the blank whole poplar controls, no obvious signs of toxic effects were observed in the exposed whole poplars. Daily monitoring showed that tran- spiration rates of exposed whole poplars (from 10 to $70 \mathrm{~mL} \mathrm{~d}^{-1}$ ) were relatively constant for individual poplars during the 20-day exposure, indicating a lack of toxicity or negative effects.

\subsection{Blank controls}

Blank controls, without PCBs in hydroponic solutions, were used to measure the contamination of volatilized PCBs to poplar shoots. Small amounts of PCBs (total PCB $0.01-0.9 \mathrm{mg} \mathrm{kg}^{-1}$ ) were detected on the main stems of blank controls, while no PCBs were detected in the solutions, roots, secondary stems and petioles, and leaves. This suggests that the woody stems of experimental trees accumulated more PCBs than did the leaves. Similarly, a high accumulation of PAHs on bark (but less on leaves) was observed by Simonich and Hites (Simonich and Hites, 1994a). They found that tree bark has higher lipid content than leaves; lipid in white pine bark (170 mg per dry weight) is higher than in its needles $(23 \mathrm{mg})$, and lipid in sugar maple bark $(33 \mathrm{mg})$ is higher than in
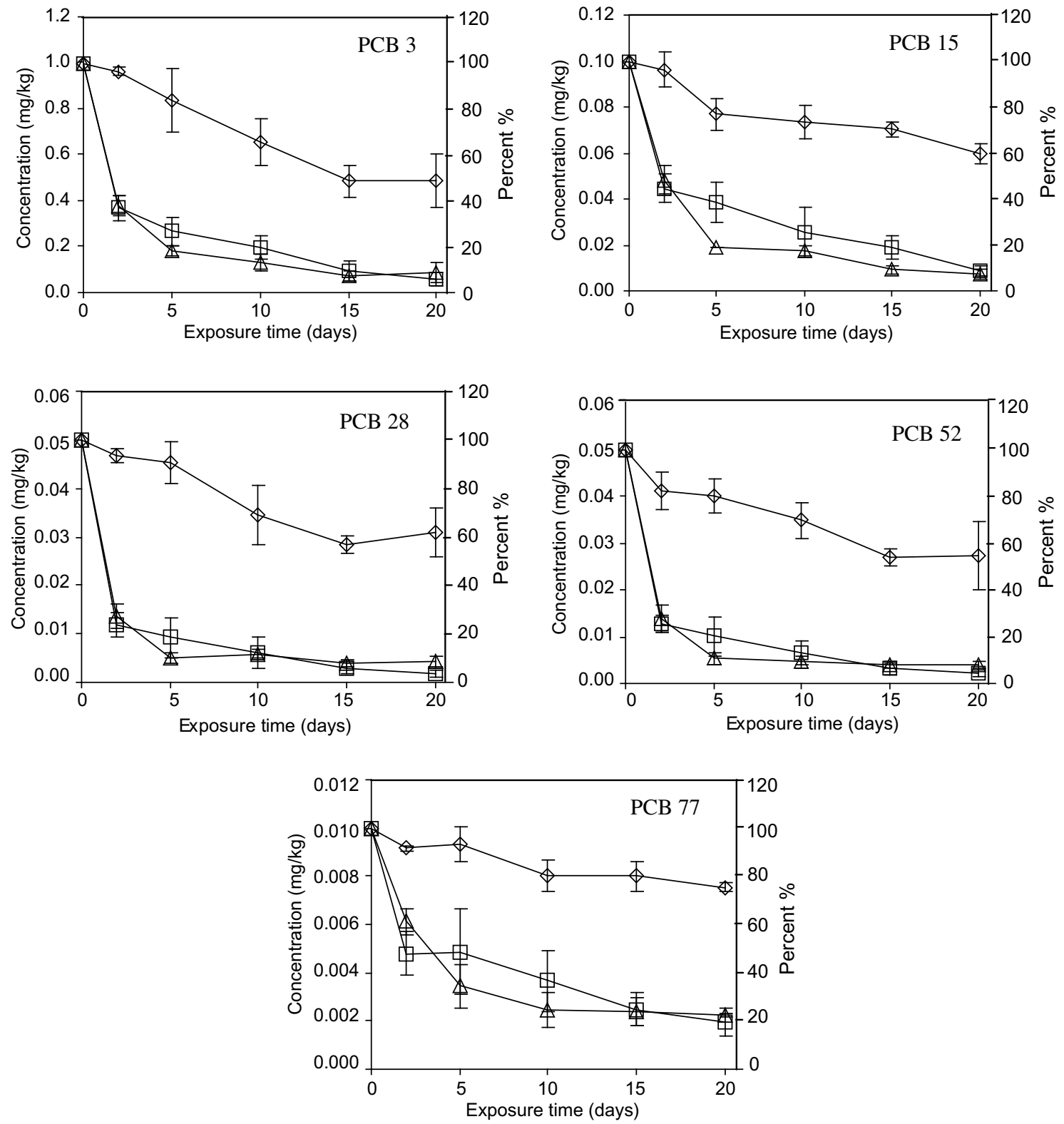

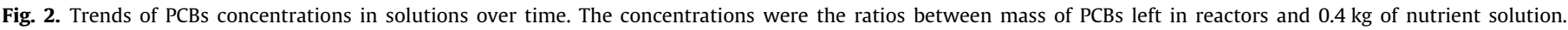
$\diamond$ : Unplanted controls $(n=3) . \triangle$ : Excised controls $(n=3)$. $\square$ : Exposed whole poplar plants $(n=5)$. 
its leaves (16 mg). Vegetation with high lipid content generally has a higher PAH concentration (Simonich and Hites, 1994b).

\subsection{Removal of $P C B$ congeners from hydroponic solutions}

Fig. 2 shows the change of PCB concentrations in hydroponic solutions over time. Unplanted controls (with glass rods protruding from the septum) were used to assess the volatilization of PCBs from the reactors, the adsorption to glass, microbial degradation and any other removal unrelated to plants. After 20 days, $51.3 \pm 11.7 \%$ of the initial mass of PCB $3,40.3 \pm 4.5 \%$ of PCB 15 , $38.0 \pm 10.1 \%$ of PCB $28,45.6 \pm 14.6 \%$ of PCB 52 and $24.5 \pm 1.9 \%$ of PCB 77 were removed from unplanted controls, mostly by volatilization. Photolysis was avoided by wrapping reactors with aluminum foil. The PCBs sorbed to glass and the septa were extracted with hexane/MTBE and added to the concentrations remaining in the reactors. Silicon sealants captured less than $1 \%$ of the PCBs spiked initially. Microbial degradation was minimized by initially sterilizing the reactors and solutions. Thus, the continuous decrease of PCB concentrations in unplanted controls was most probably caused by volatilization. It is likely that semi-volatile and hydrophobic PCB congeners diffused from the inorganic aqueous solution to the headspace and then escaped the reactor. Sealing the reactors (as best possible) merely slowed down the volatilization loss. This was confirmed as PCB 3, the most volatile selected congener, showed the greatest losses.

For excised controls and exposed whole plants, concentrations fell sharply in the first five days and then continued decreasing slowly. At 20 days, over $91 \%$ of the initial mass of PCB 3, PCB 15 , PCB 28, and PCB 52, and about $80 \%$ of PCB 77 had been removed from the solutions of both the excised controls and the exposed whole poplars. The similarity of removal suggests that transpiration had little effect on the overall removal of PCBs. For hydrophilic and water miscible chemicals, such as dioxane and RDX, removal from hydroponic solution, translocation within plants, and emission from leaves are transpiration-driven, and a linear relationship
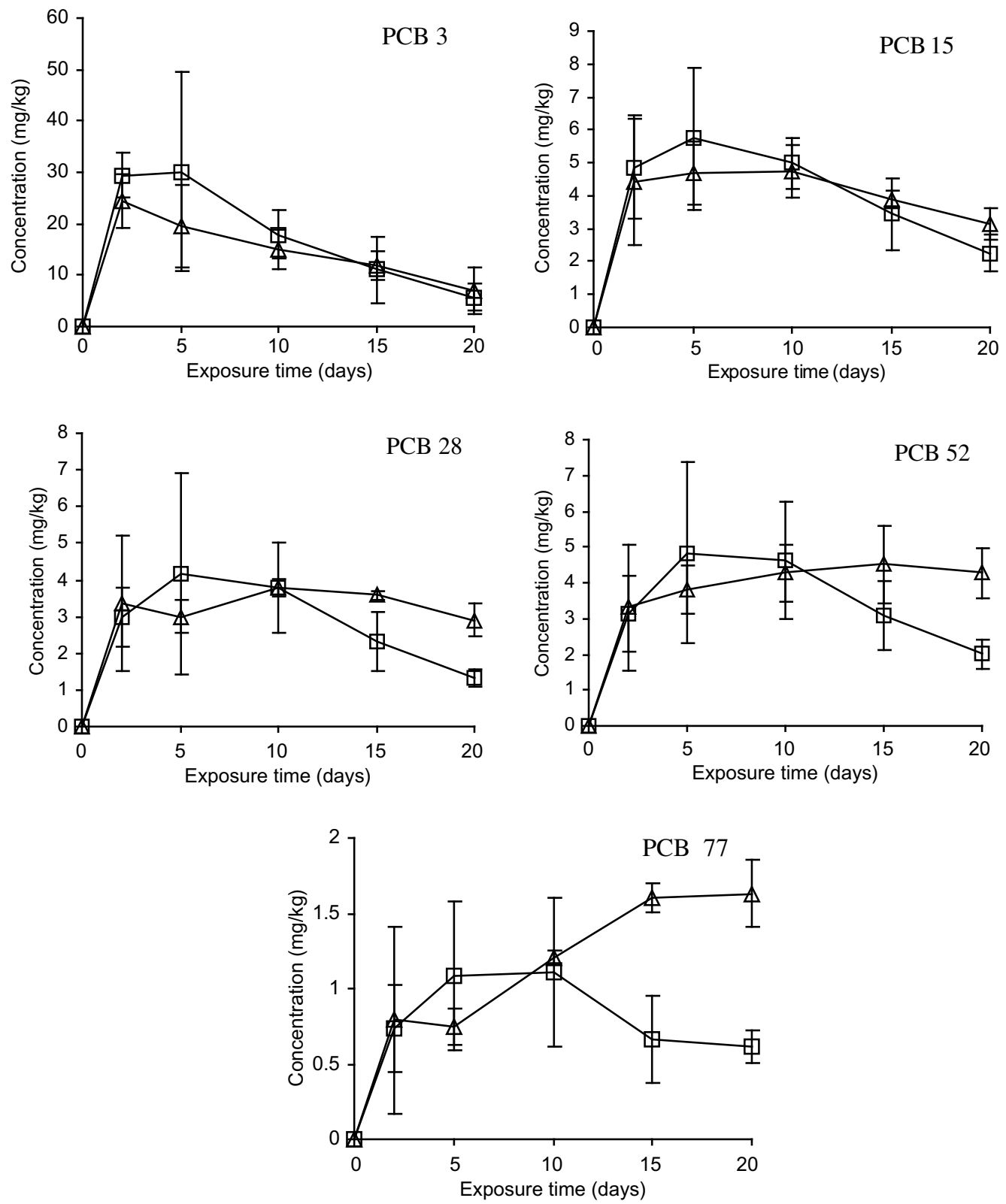

Fig. 3. Concentrations of PCB congeners associated with roots (fresh weight) over time. $\triangle$ : Excised controls $(n=3)$. $\square$ : Exposed whole poplar plants ( $n=5$ ). 
exists between chemical removal and transpiration (Aitchison et al., 2000). In our studies, there was no such linear relationship between transpiration and chemical removal rate for PCBs indicating transpiration and volatilization are not the predominant removal mechanism.

Concentrations of PCBs in the solutions of excised controls were slightly less than that of whole poplars during 15 days exposure. This could be due to the degradation of PCBs by microbes from the dead roots. None of the poplars were sterilized so microorganisms associated with plants could affect the fate of PCBs. Solutions of excised controls became visibly turbid after several days suggesting significant bacterial growth in those reactors.

\subsection{The PCBs associated with roots}

Polychlorinated biphenyls were sorbed to the roots, and the sorption of lesser-chlorinated PCBs should be relatively reversible based on their moderate solubility (Dietz and Schnoor, 2001). We observed competitive partitioning for PCBs in the reactors including partitioning between the solution and the plant, the solution and glass, the solution and headspace, headspace and the plant, and headspace and glass. Polychlorinated biphenyls were sorbed first to roots and subsequently desorbed, diffused to the headspace, competitively sorbed to the bark, to the glass, and a small fraction exited the reactor by volatilization from the seal or bark. The reactors were not in chemical equilibrium because of continuous volatilization losses and possibly small amounts of microbial degradation.

The concentration of PCBs associated with the roots of excised controls was measured (Fig. 3). PCB 3 decreased sharply after two days, and the concentration at 20 days was only $28 \%$ of that at two days. The concentration of PCB 15 decreased significantly after 10 days. Concentrations of PCB 28 and 52 leveled off, while PCB 77 increased throughout the exposure period for excised controls. This suggested that congeners with higher volatility and lower hydrophobicity (lower $\log K_{\text {ow }}$ ), such as PCB 3 and 15, desorbed readily from roots and were lost from the reactors by volatilization. But the more hydrophobic congeners were bound strongly to roots and stems and were not readily lost from the reactors. For PCB 77, the difference between the patterns of removal in the excised control and the planted reactor is a measure of the amount of translocation and transformation by living plant tissue.

In Fig. 3, the PCB concentrations associated with exposed whole poplar roots increase within the first five days and then decrease after 10 days. Unlike the excised controls, roots of whole intact poplars grew throughout the experiment and increased their biomass. But the masses of PCBs on whole poplar roots were nevertheless reduced after five days. Such a large decrease in PCB concentrations on roots could not have been caused by growthdilution, but rather due to translocation and transformation by poplars.

The accumulation of PCBs associated with roots could be evaluated by the root concentration factor (RCF) (Briggs et al., 1982), the ratio of what is detected on roots (milligrams per kilogram of fresh root tissue) compared to what is detected in the hydroponic solution (milligrams per kilogram of solution). It was determined that PCB 77 in solution was still saturated at 20 days. The RCF for PCB 77 was calculated using its water solubility as its solution concentration. Other congeners were calculated using daily measurements. The highest RCF over 20 days for PCB 3, 15, 28, 52 and 77 were 185, 568, 1494, 1828 and 1965, respectively. Congeners with greater hydrophobicity, such as PCB 77, had a larger RCF as well as a greater tendency to partition out of the aqueous phase and onto roots.

Previous investigators studied the sorption of chemicals to dead roots and related the RCF and $\log \mathrm{K}_{\mathrm{ow}}$ with the following equations: $\log (\mathrm{RCF}-3.0)=0.65 \log K_{\text {ow }}-1.57$ (Burken and Schnoor, 1998) $\log (\mathrm{RCF}-0.82)=0.77 \log K_{\text {ow }}-1.52$ (Briggs etal., 1982)

Both equations were based on hydroponic exposure studies using the BTEX chemical suite whose $\log K_{\text {ow }}$ ranged from 0.87 to 4.25 , and pentachlorophenol with a $\log K_{\text {ow }}$ of 5.04. The highest RCF was 30 (Burken and Schnoor, 1998), which was far lower than that in this study. The $\log \mathrm{RCF}$ and $\log K_{\mathrm{ow}}$ of PCBs were correlated linearly for both excised controls and exposed whole poplars at all tested exposure times (Fig. 4a).

Fig. $4 \mathrm{~b}$ combines the $\log \mathrm{RCF}$ vs $\log K_{\mathrm{ow}}$ correlation calculated in this study and from the data by Burken and Schnoor (1998) after five days sorption equilibrium. A linear relationship exists between $\log$ RCF and $\log K_{\text {ow }}$. The functional relationship between RCF and $\mathrm{K}_{\mathrm{ow}}$ is

$\mathrm{RCF}=0.1047 \cdot \mathrm{K}_{\mathrm{ow}}^{0.5881} \quad r^{2}=0.9072$

The results suggest that the hydrophobic chemicals with $\log K_{\mathrm{ow}}>5$ sorb strongly to the plant roots and are difficult to translocate

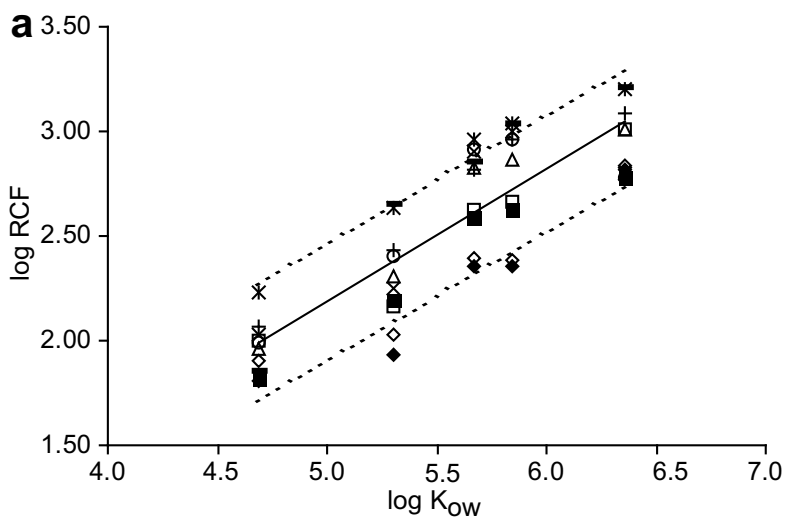

$\diamond$ EWP 2days $\square$ EWP 5days $\triangle$ EWP 10days $\times$ EWP 15days o EWP 20days - ETC 2days —ETC 5days + ETC 10days * ETC 15days - ETC 20days

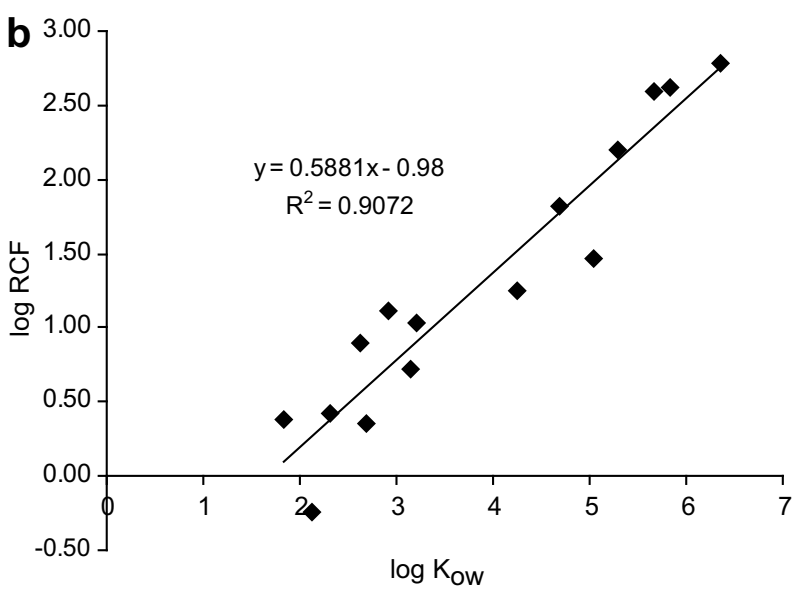

Fig. 4. (a) Linear relationship between $\log$ RCF and $\log K_{\text {ow }}$ for PCBs in exposed whole poplars (EWP) and excised tree controls (ETC) (this study). The minimal and maximal RCF occurred on excised roots at 2 and 15 days (dotted lines), with equations of $Y=0.62 X-1.19\left(r^{2}=0.9316\right)$ and $Y=0.61 X-0.59\left(r^{2}=0.9623\right)$, respectively. The solid line represents the average logRCF for all root samples, with an equation of $Y=0.63 X-0.99\left(r^{2}=0.9486\right)$. (b) Linear relationship between $\log$ RCF and $\log K_{\text {ow }}$ for selected aromatic xenobiotic chemicals including nitrobenzene, benzene, trichloroethylene, atrazine, toluene, chlorobenzene, ethylbenzene, $m$-xylene, trichlorobenzene, and pentachlorophenol. Data comprise of log RCF of PCBs of excised roots at five days and that from Burken and Schnoor (1998). 
within the plant. It extends the previous analysis by Briggs et al. (1982) and Burken and Schnoor (1998) to more hydrophobic substances.

\subsection{Uptake of PCBs by poplar roots}

To distinguish surface sorption versus the uptake of PCBs inside roots, samples of intact roots were extracted with hexane/acetone, while powdered roots were finely ground, extracted and analyzed. The differences between them are likely due to PCBs entering inside root tissues. After 20 days, the concentrations of PCB 3, 15, 28,52 and 77 inside the roots of excised controls were $0.14,0.08$, $0.11,0.33$ and $0.12 \mathrm{mg} \mathrm{kg}^{-1}$, inside the roots of exposed whole poplars concentrations were $1.07,0.49,0.25,0.38$, and $0.17 \mathrm{mg} \mathrm{kg}^{-1}$, respectively. For the excised controls, most of the PCB congeners, over 92\% of roots PCBs, were present on the surface of the roots. For the whole poplar plants, a greater proportion of the PCB congeners were found inside the root tissue after 20 days.

\subsection{Accumulation of PCBs in the main stem}

The trends of PCB concentrations in the main stem over time are depicted in Fig. 5. Contamination from the air by volatilized PCBs

Table 1

PCBs mass distribution in main stems of exposed whole poplars at 20 days

\begin{tabular}{llllll}
\hline Compartment & $\begin{array}{l}\text { PCB 3 } \\
(\mu \mathrm{g})\end{array}$ & $\begin{array}{l}\text { PCB 15 } \\
(\mu \mathrm{g})\end{array}$ & $\begin{array}{l}\text { PCB 28 } \\
(\mu \mathrm{g})\end{array}$ & $\begin{array}{l}\text { PCB 52 } \\
(\mu \mathrm{g})\end{array}$ & $\begin{array}{l}\text { PCB 77 } \\
(\mu \mathrm{g})\end{array}$ \\
\hline Top bark & $0.86^{\mathrm{a}}$ & n.d. $^{\mathrm{b}}$ & n.d. & n.d. & n.d. \\
Top wood & 0.70 & n.d. & n.d. & n.d. & n.d. \\
Middle bark & 49.54 & 4.88 & 2.35 & 1.86 & 0.05 \\
Middle wood & 9.13 & 0.02 & 0.02 & n.d. & n.d. \\
Bottom bark & 81.19 & 12.06 & 5.15 & 4.61 & 0.39 \\
Bottom wood & 33.30 & 1.68 & 0.39 & 0.19 & n.d. \\
\hline
\end{tabular}

Mean value $(n=2)$

b No PCB were detected in the samples.
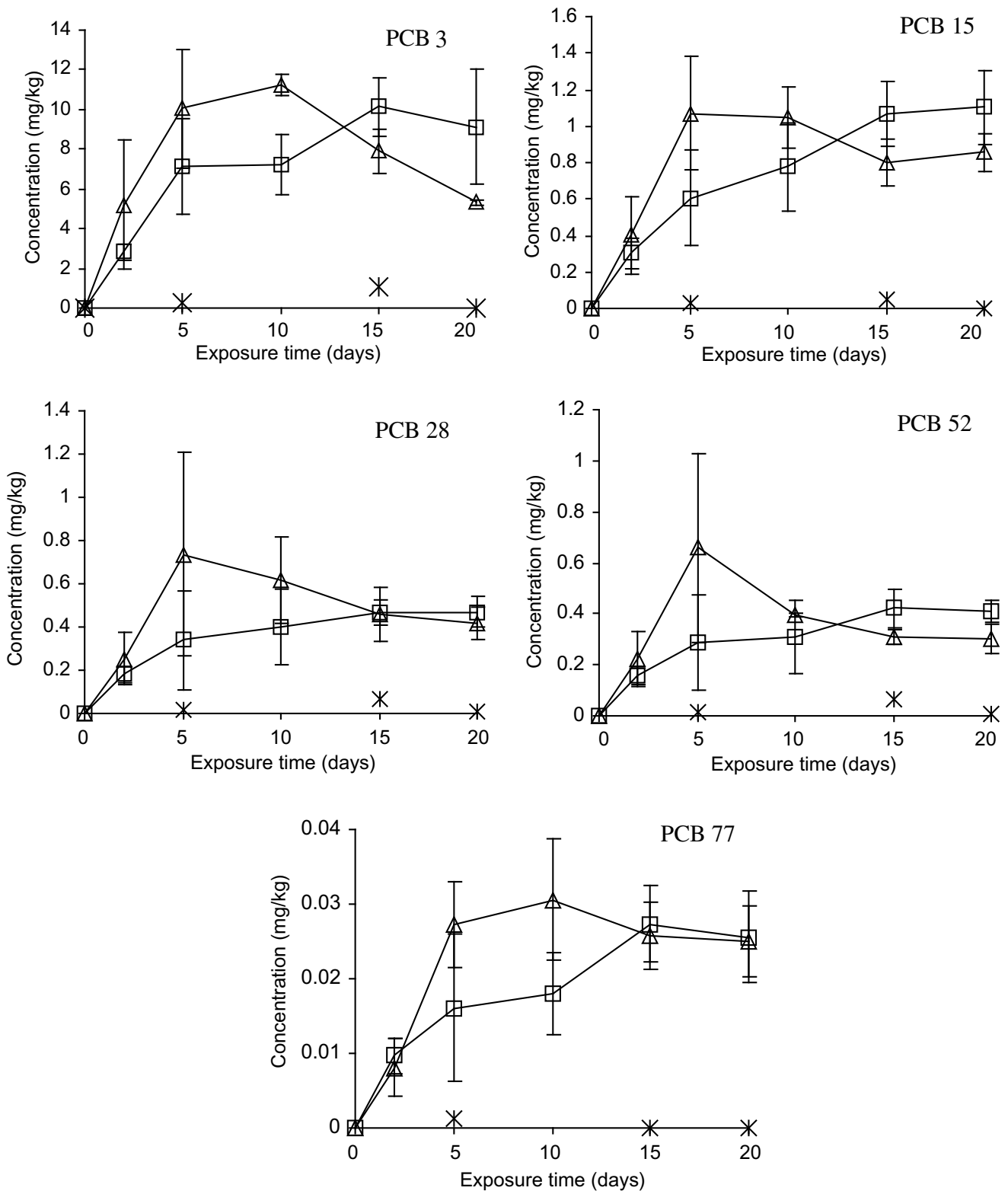

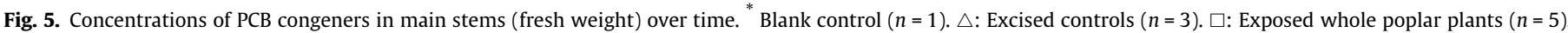


resorbing to the stems and leaves was very small, as shown by the blank controls. For excised controls, PCB concentrations on the main stems decreased after reaching peak values, and desorption was similar to that of the excised roots. The concentrations of all PCBs inside and on the main stem of the whole poplar plants increased steadily during the 20-day experiment. A small amount of PCB 3 was detected in eight out of thirteen samples in the stem outside the reactor, and $\mathrm{PCB}$ congeners 15 and 28 were detected in four samples from the top stem. Neither PCB 52 nor 77 was detected in the top stem. The majority of PCBs on the main stems was comprised of PCBs from inside the reactor. There was little translocation.

Two of the main stems sampled at 20 days were subdivided and analyzed in more detail. The results listed in Table 1 show the translocation pathway of PCBs. The middle and the bottom main stems were located inside the reactor. This bark sorbed more PCBs from solution and headspace than was translocated from roots; more $\mathrm{PCBs}$ were found on the bark than inside the stem. Bark has been shown to strongly bind hydrophobic chemicals (Simonich and Hites, 1994a,b). Similar amounts of PCB 3 were detected in both the top bark and the top wood, indicating significant translocation. Whether in bark or wood, the mass of PCBs decreased markedly from the bottom to the top of the stems. Translocation of PCB 3 from the bottom to the top stem through the wood was readily apparent, as was some translocation of PCB 15 and 28. However, no translocation was observed for PCB 52 and 77. The ability of congeners to move up the stem was related to their hydrophobicity $\left(\log K_{\text {ow }}\right)$; hydrophobic congeners were translocated with more difficulty. PCB 77, the most hydrophobic of the selected congeners, was bound in roots tissues after uptake and did not translocate within the poplar.

\subsection{The PCBs in shoots}

Shoot samples including leaves, secondary stems and petioles were analyzed. No PCBs were detected in any leaf samples. For secondary stems and petioles, no PCBs were found in samples after two days. In secondary stems from five to 20 days, PCBs 28, 52, and 77 were not detected, but small amounts of PCB 3 and 15 were detected in ten and one out of eighteen samples, respectively. PCB 15 was also detected in two out of three second- ary stems in a preliminary 30-day experiment (in which higher initial concentrations were used). If they were detected in the secondary stems and petioles, PCB 3 and 15 were also detected in the top main stems. In addition, there was no PCB detected in secondary stems of blank controls. Therefore, it was concluded that PCB 3 and 15 translocated from hydroponic solution to the shoots of poplars and could not have emanated from sorption from the atmosphere.

PCB 28, 52, and 77 were not translocated to the upper portions of the poplar plants in these experiments. These results differ from those of Zeeb and coworkers (Whitfield-Aslund et al., 2007) in which they found that PCBs, even penta-, hexa- and hepta-chlorinated congeners, were taken up and translocated in pumpkins after planting in highly contaminated soil (total PCB $46 \mathrm{mg} \mathrm{kg}^{-1}$, mean value) for 10 weeks. It was confirmed that the fate of PCBs varies in different plant species.

\subsection{Mass balance in reactors}

The distributions of PCBs in different compartments in the reactors after 20 days are shown in Table 2 . For exposed whole poplars, $41.2 \%$ of initial mass of PCB 3 was associated with the main stems. As the most volatile congener, about $45 \%$ of initial PCB 3 was not recovered and was likely lost by evaporation from the reactor seal and by volatilization from the stem. The total recovery of PCB 3 was only $55.0 \%$. Mass balances of other congeners were complete to within $\pm 15 \%$. The largest portions of PCB 15,28 , and 52 were accumulated on the roots and the main stems. Accumulation on roots and stems was related to the hydrophobicity and volatility of PCB congeners. For PCB 77, 81.0\% was detected on the roots alone.

The total recovery of PCBs from exposed whole poplars was higher than that of excised tree controls and unplanted controls because the roots and stems could take up PCBs, and this decreased the volatilization loss from the reactors. Compared to the average biomass of roots from excised controls ( $1.23 \mathrm{~g}$ in 20-day samples), exposed whole poplars had more root mass ( $5.47 \mathrm{~g}$, mean value) due to growth, and they sorbed more PCBs. This was one of the reasons for the differences in $\mathrm{PCB}$ recovery between whole poplars and excised controls. Another reason was the biodegradation of PCBs by dead roots in excised controls, as evidenced by more rapid

Table 2

Mass balances and PCBs distribution (\% of mass applied) in the exposed whole poplar (EWP), excised tree controls (ETC) and unplanted controls (UPC) at 20 days ${ }^{\mathrm{a}}$

\begin{tabular}{|c|c|c|c|c|c|c|c|c|c|}
\hline Compound & Reactors & Solution & Roots & $\begin{array}{l}\text { Main stem inside of } \\
\text { reactor }\end{array}$ & $\begin{array}{l}\text { Main stem out of } \\
\text { reactor }\end{array}$ & $\begin{array}{l}\text { Secondary stem and } \\
\text { petioles }\end{array}$ & Leaves & $\begin{array}{l}\text { Silicon } \\
\text { sealant }\end{array}$ & $\begin{array}{l}\text { Total } \mathrm{PCBs} \\
\text { recovered }^{\mathrm{b}}\end{array}$ \\
\hline \multirow[t]{3}{*}{ PCB 3} & EWP & $5.83 \pm 2.70^{c}$ & $6.51 \pm 1.70$ & $41.16 \pm 3.01$ & \multirow[t]{3}{*}{$0.74 \pm 0.76$} & $0.39 \pm 0.49$ & n.d. ${ }^{d}$ & $0.32 \pm 0.15$ & $54.96 \pm 2.66$ \\
\hline & ETC & $8.75 \pm 4.54$ & $2.20 \pm 1.42$ & $30.84 \pm 5.02$ & & $--^{e}$ & - & $0.33 \pm 0.17$ & $42.12 \pm 9.31$ \\
\hline & UPC & $48.71 \pm 11.74$ & - & - & & - & - & $0.30 \pm 0.07$ & $49.01 \pm 11.68$ \\
\hline \multirow[t]{3}{*}{ РCB 15} & EWP & $8.86 \pm 2.06$ & $29.35 \pm 11.75$ & $52.37 \pm 8.32$ & \multirow[t]{3}{*}{$0.06 \pm 0.14$} & n.d. & n.d. & $0.15 \pm 0.19$ & $90.79 \pm 6.18$ \\
\hline & ETC & $7.17 \pm 2.29$ & $9.77 \pm 2.35$ & $43.99 \pm 1.45$ & & - & - & $0.03 \pm 0.06$ & $60.97 \pm 3.56$ \\
\hline & UPC & $59.65 \pm 4.52$ & - & - & & - & - & $0.22 \pm 0.08$ & $59.88 \pm 4.46$ \\
\hline \multirow[t]{3}{*}{ РСВ 28} & EWP & $3.45 \pm 1.37$ & $35.30 \pm 14.87$ & $44.94 \pm 8.23$ & \multirow[t]{3}{*}{ n.d. } & n.d. & n.d. & $0.57 \pm 0.57$ & $84.27 \pm 12.18$ \\
\hline & ETC & $8.31 \pm 2.34$ & $18.08 \pm 4.39$ & $42.51 \pm 2.81$ & & - & - & $0.64 \pm 0.66$ & $69.55 \pm 9.87$ \\
\hline & UPC & $62.01 \pm 10.09$ & - & - & & - & - & $0.60 \pm 0.17$ & $62.61 \pm 9.98$ \\
\hline \multirow[t]{3}{*}{ РСВ 52} & EWP & $4.55 \pm 1.79$ & $52.43 \pm 23.08$ & $39.95 \pm 9.87$ & \multirow[t]{3}{*}{ n.d. } & n.d. & n.d. & $0.53 \pm 0.56$ & $97.46 \pm 18.04$ \\
\hline & ETC & $7.86 \pm 1.81$ & $26.16 \pm 2.74$ & $32.76 \pm 2.71$ & & - & - & $0.63 \pm 0.67$ & $67.41 \pm 6.42$ \\
\hline & UPC & $54.44 \pm 14.57$ & - & - & & - & - & $0.51 \pm 0.20$ & $54.95 \pm 14.45$ \\
\hline \multirow[t]{3}{*}{ РСВ 77} & EWP & $19.71 \pm 5.91$ & $81.04 \pm 35.56$ & $12.56 \pm 4.97$ & \multirow[t]{3}{*}{ n.d. } & n.d. & n.d. & n.d. & $113.31 \pm 24.85$ \\
\hline & ETC & $22.75 \pm 0.73$ & $50.60 \pm 11.33$ & $12.14 \pm 1.70$ & & - & - & n.d. & $85.50 \pm 12.83$ \\
\hline & UPC & $75.46 \pm 1.87$ & - & - & & - & - & n.d. & $75.46 \pm 1.87$ \\
\hline
\end{tabular}

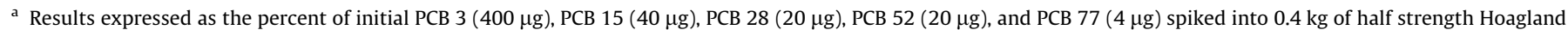
solution.

b The summation of different compartment.

c Mean value \pm standard deviation, for exposed whole poplars, $n=5$, for excised tree controls and unplanted controls, $n=3$, respectively.

d Not detected.

e No sample for detection. 
degradation in concentration and the optical density (turbidity) of the solutions.

\section{Conclusions}

Our observations indicate that the woody stem of a poplar plant accumulates more PCBs than the leaves in hydroponic exposure. The sorption, uptake, and translocation behavior of PCBs within hybrid poplars were related to the hydrophobicity of the congeners. Mono- and di-chlorinated congeners, with $\log K_{\text {ow }}$ ranging from 4.17 to 5.54 (Dickerson and Korte, 1994), represented by PCB 3 and 15, were translocated from the roots to the secondary stem. Tri-chlorinated PCB 28 was translocated to the main stem but not farther. Tetra-chlorinated PCB 52 and 77, with higher log$K_{\text {ow }}$ values, were bound strongly to roots tissues and were prevented from entering the transpiration stream.

The potential phytoremediation for persistent toxic PCBs in moist settings like confined disposal facilities is most practicable by phytostabilization and rhizosphere bioremediation using trees, such as hybrid poplars with their deep rooting capabilities and large transpiration rates for hydraulic control. This research indicates that hybrid poplars could be used to take up and bind semi-volatile PCB congeners with little loss to their surroundings.

\section{Acknowledgments}

This work was supported by the NIEHS Superfund Basic Research Program (SBRP), Grant Number P42ES13661. We thank Hans-Joachim Lehmler, SBRP Center, University of Iowa for providing PCB standards. This is a contribution from the W.M. Keck Phytotechnology Laboratory at the University of Iowa.

\section{Appendix A. Supplementary material}

Supplementary data associated with this article can be found, in the online version, at doi:10.1016/j.chemosphere.2008.08.009.

\section{References}

Aitchison, E.W., Kelley, S.L., Alvarez, P.J.J., Schnoor, J.L., 2000. Phytoremediation of 1,4-dioxane by hybrid poplar trees. Water Environ. Res. 72, 313-321.

Briggs, G.G., Bromilow, R.H., Evans, A.A., 1982. Relationships between lipophilicity and root uptake and translocation of non-ionised chemicals by barley. Pestic. Sci. 13, 495-504.

Burken, J.G., Schnoor, J.L., 1998. Predictive relationships for uptake of organic contaminants by hybrid poplar trees. Environ. Sci. Technol. 32, 3379-3385.

Dickerson, K.S., Korte, N.E., 1994. Polychlorinated Biphenyls And Their Interaction with the Environment. Oak Ridge National Laboratory, Martin Marietta Energy System, Inc.

Dietz, A.C., Schnoor, J.L., 2001. Advance in phytoremediation. Environ. Health Perspect. 109, 163-168.

Epstein, E., 1972. Mineral Nutrition of Plants: Principles and Perspectives. John Wiley \& Sons, New York.
Fries, G.F., Marrow, G.S., 1981. Chlorobiphenyl movement from soil to soybean plants. J. Agric. Food Chem. 29, 757-759.

Gan, R., Berthouex, P., 1994. Disappearance and crop uptake of PCBs from sludgeamended farming. Water Environ. Res. 66, 54-69.

Hornbuckle, K.C., Carlson, D.L., Swackhamer, D.L., Baker, J.E., Eisenreich, S.J., 2006. Polychlorinated biphenyls in the Great Lakes. Hdb Environ. Chem. 5, 13-70. Part $\mathrm{N}$.

Hughes, J.B., Shanks, J., Vanderford, M., Lauritzen, J., Bhadra, R., 1997. Transformation of TNT by aquatic plants and plant tissue cultures. Environ. Sci. Technol. 31, 266-271.

Hulster, A., Muller, J., Marschner, H., 1994. Soil-plant transfer of polychlorinated dibenzo-p-dioxins and dibenzofurans to vegetables of the cucumber family (Cucurbitaceae). Environ. Sci. Technol. 28, 1110-1115.

Iwata, Y., Gunther, F.A., 1976. Translocation of the polychlorinated biphenyl Aroclor 1254 from soil to carrots under field conditions. Arch. Environ. Contam. Toxicol. 4, 44-59.

Mackova, M., Barriault, D., Francova, K., Sylvestre, M., Moder, M., Vrchotova, B. Lovecka, P., Najmanova, J., Demnerova, K., Novakova, M., Rezek, J., Macek, T. 2006. Phytoremediation of polychlorinated biphenyls. In: Mackova, Martina, Dowling, David, Macek, T. (Eds.), Phytoremediation Rhizoremediation. Springer, pp. 143-168.

Maddox, C., Wang, B., Kirby, P.A., Wang, K., Ludewig, G., 2008. Mutagenicity of 3methylcholanthrene, $\mathrm{PCB} 3$, and 4-OH-PCB3 in the lung of transgenic BigBlue rats. Environ. Toxicol. Pharmacol. 25, 260-266.

Ptak, A., Ludewig, G., Robertson, L., Lehmler, H.J., Gregoraszczuk, E.L., 2006. In vitro exposure of porcine prepubertal follicles to 4-chlorobiphenyl (PCB3) and its hydroxylated metabolites: effects on sex hormone levels and aromatase activity. Toxicol. Lett. 164, 113-122.

Risebrough, R.W., Walker, W., Schmidt, T.T., DeLappe, B.W., Connors, C.W. 1976. Transfer of chlorinated biphenyls to Antarctica. Nature 264 (5588), 738-739.

Sawhney, B.L., Hankin, L., 1984. Plant contamination by PCBs from amended soil. J. Food Prot. 47, 232-236.

Schnoor, J.L., Licht, L.A., McCutcheon, S.C., Wolfe, N.L., Carriera, L.H., 1995 Phytoremediation of organic and nutrient contaminants. Environ. Sci. Technol 29, 318A-323A.

Simonich, S.L., Hites, R.A., 1994a. a. Importance of vegetation in removing polycyclic aromatic hydrocarbons from the atmosphere. Nature 370, 49-51.

Simonich, S.L., Hites, R.A., 1994b. Vegetation-atmosphere partitioning of polycyclic aromatic hydrocarbons. Environ. Sci. Technol. 28, 939-943.

Sporring, S., Bøwadt, S., Svensmark, B., Bjorklund, E., 2005. Comprehensive comparison of classic Soxhlet extraction with Soxtec extraction ultrasonication extraction, supercritical fluid extraction, microwave assisted extraction and accelerated solvent extraction for the determination of polychlorinated biphenyls in soil. J. Chromatogr. A 1090, 1-9.

Tang, N.H., Myers, T.E., 2002. PCB removal from contaminated dredged material. Chemosphere 46, 477-484.

Webber, M.D., Pietz, R.I., Granato, T.C., Svoboda, M.L., 1990. Plant uptake of PCBs and other organic contaminants from sludge-treated coal refuse. J. Environ. Qual. 23 1019-1026.

Weber, J.B., Mrozek, E., 1979. Polychlorinated biphenyls: phytotoxicity, absorption and translocation by plants and inactivated carbon. Bull. Environ. Contam. Toxicol. 23, 412-417.

White, J., Parrish, Z., Isleyen, M., Gent, M., Iannucci-Berger, W., Eitzer, B., Kelsey, J. Mattina, M., 2006. Influence of citric acid amendments on the availability of weathered PCBs to plant and earthworm species. Int. J. Phytorem. 8, 63-79.

Whitfield-Aslund, M.L., Zeeb, B.A., Rutter, A., Reimer, K.J., 2007. In situ phytoextraction of polychlorinated biphenyl (PCB) contaminated soil. Sci. Total Environ. 374, 1-12.

Wyrzykowska, B., Bochentin, I., Hanari, N., Orlikowska, A., Falandysz, J., Yuichi, H. Yamashita, N., 2006. Source determination of highly chlorinated biphenyl isomers in pine needles-comparison to several PCB preparations. Environ. Pollut. 143, 46-59.

Zeeb, B.A., Amphlett, J.S., 2006. Potential for phytoremediation of polychlorinated biphenyl (PCB) contaminated soil. Int. J. Phytorem. 8, 199-221. 